Article

\title{
Micellar Iron Oxide Nanoparticles Coated with Anti-Tumor Glycosides
}

\author{
Hugo Groult ${ }^{1}$, Isabel García-Álvarez ${ }^{2,3}$ (i) , Lorenzo Romero-Ramírez ${ }^{4}$ (D), \\ Manuel Nieto-Sampedro ${ }^{4,5}$, Fernando Herranz ${ }^{6}$, Alfonso Fernández-Mayoralas 7 (i) \\ and Jesús Ruiz-Cabello ${ }^{8,9}$ * (iD) \\ 1 UMR CNRS 7266 LIENSs, Approches Moléculaires Environnement-Santé Environnement (AMES), \\ Avenue Michel Crepeau, Université de La Rochelle, 86073 La Rochelle, France; hugo.groult@univ-lr.fr \\ 2 Department of Biological Engineering, Massachussetts Institute of Technology, 77 Massachusetts Avenue, \\ Cambridge, MA 02139, USA; ialvarez@mit.edu \\ 3 Faculty of Experimental Sciences, Francisco de Vitoria University (UFV), Ctra. Pozuelo-Majadahonda \\ Km 1.800, Pozuelo de Alarcón, 28223 Madrid, Spain \\ 4 Hospital Nacional de Parapléjicos, SESCAM, Finca la Peraleda s/n, 45004 Toledo, Spain; \\ lromeroramirez@sescam.jccm.es (L.R.-R.); mnietosampedro@gmail.com (M.N.-S.) \\ 5 Instituto Cajal, CSIC, Avda. Doctor Arce 37, 28002 Madrid, Spain \\ 6 Advanced Imaging Unit, Centro Nacional de Investigaciones Cardiovasculares Carlos III (CNIC), \\ 28029 Madrid, Spain; fernando.herranz@cnic.es \\ 7 Instituto de Química Orgánica General, CSIC, Juan de la Cierva, 3, 28006 Madrid, Spain; \\ alfonso.mayoralas@csic.es \\ 8 CIC biomaGUNE and Ciber de Enfermedades Respiratorias, Parque Científico y Tecnológico de Gipuzkoa, \\ Paseo Miramón 182, 20014 Donostia/San Sebastián, Gipuzkoa, Spain \\ 9 CIBER de Enfermedades Respiratorias (CIBERES), 28029 Madrid, Spain \\ * Correspondence: jruizcabello@cicbiomagune.es; Tel.: +34-943-005-300
}

Received: 7 June 2018; Accepted: 23 July 2018; Published: 25 July 2018

\begin{abstract}
The synthesis procedure of nanoparticles based on thermal degradation produces organic solvent dispersible iron oxide nanoparticles (OA-IONP) with oleic acid coating and unique physicochemical properties of the core. Some glycosides with hydrophilic sugar moieties bound to oleyl hydrophobic chains have antimitotic activity on cancer cells but reduced in vivo applications because of the intrinsic low solubility in physiological media, and are prone to enzymatic hydrolysis. In this manuscript, we have synthetized and characterized OA-IONP-based micelles encapsulated within amphiphilic bioactive glycosides. The glycoside-coated IONP micelles were tested as Magnetic Resonance Imaging (MRI) contrast agents as well as antimitotics on rat glioma (C6) and human lung carcinoma (A549) cell lines. Micelle antimitotic activity was compared with the activity of the corresponding free glycosides. In general, all OA-IONP-based micellar formulations of these glycosides maintained their anti-tumor effects, and, in one case, showed an unusual therapeutic improvement. Finally, the micelles presented optimal relaxometric properties for their use as T2-weighed MRI contrast agents. Our results suggest that these bioactive hydrophilic nano-formulations are theranostic agents with synergistic properties obtained from two entities, which separately are not ready for in vivo applications, and strengthen the possibility of using biomolecules as both a coating for OA-IONP micellar stabilization and as drugs for therapy.
\end{abstract}

Keywords: glycoside; iron oxide nanoparticles; nanomicelles; antitumoral 


\section{Introduction}

Nanotechnology has important applications in biomedicine, mainly in the field of cancer treatment [1]. The singular structural properties of nanoparticles (NP) permit the design of drug delivery platforms that easily answer the main problems of chemotherapeutically based tumor treatments, especially adding the specificity of an anti-tumoral drug without disturbing healthy cells and tissues [2,3]. The use of nanotechnology introduces targeting options either by passive accumulation of the NP inside tumor cells resulting from enhanced permeability and retention effect (EPR) or active ligand-mediated targeting [4-6]. Suitable targeting agents often improve pharmacokinetics, e.g., local delivery with improved dosing, membrane permeation as well as a reduced toxicity or minimum side effects by specific release of the therapeutic cargo in the target tissues $[7,8]$. Within the large number of nanomaterials, superparamagnetic iron oxides (IONP) are particularly interesting for their capability to direct drugs at the pathological area mediated by an external, internally implanted, or even spatially directed magnetic field $[9,10]$. Furthermore, IONP can act as contrast agents for MRI, providing diagnostic capabilities to the therapeutic agent [11,12]. Several studies of magnetically driven drug targeting in small animal models and clinical trials have successfully reported partial remission of the tumor [13,14]. Finally, there is a growing interest in the use of IONP for hyperthermia applications [15].

A family of synthetic glycosides was proposed as inhibitors of glioma and adenocarcinoma cell proliferation $[16,17]$. These glycosides are derivatives of $N$-acyl-D-glucosamine and previous results indicate that their activity increase when a long hydrocarbon chain was present at the C-1 position of the glycoside moiety. Other groups have shown that the conjugation of a sugar with an oleyl chain improves the antitumoral activity of the conjugate [18]. The proposed mechanism of growth inhibition suggests alterations in lipid metabolism. Indeed, it has been shown that glycoside-treatments caused important changes in the level of glycosphingolipids $[19,20]$, which have regulatory roles in tumor progression and are involved in pathways of cell death or proliferation [21-23]. However, preliminary in vivo experiments with the best candidates offered modest results [24]. Because of their long alkyl chain, the compounds were poorly soluble in aqueous physiological media and some of them were also subjected to enzymatic degradation, which reduced their biological stability [25]. Consequently, it was only possible to use intratumoral administration of drugs dispersed in a dimethyl sulfoxide (DMSO) $/ \mathrm{H}_{2} \mathrm{O}$ mixture with Bovine Serum Albumin (BSA) as carrier. Only one enzyme-resistant thioglycoside derivative showed significant tumor growth inhibitory activity with high repetitive doses $[24,26]$. These considerations indicate that IONP-based drug delivery systems may be effective for both stabilizing and targeting of the bioactive glycosides to the tumor site, leading to improved therapeutic activity.

The therapeutic agents in most IONP drug delivery systems are either covalently bound or electrostatically adsorbed onto the IONP surface, dispersed into a polymer matrix, or encapsulated into amphiphilic nanostructures [5,27]. Commonly, all these solutions require a pre-existing hydrophilic coating with functional moieties on the IONP scaffold. For the sake of simplicity, the method based on co-precipitation that yields aqueous IONP is still preferred due to the possibility of further surface tailoring, although the NP obtained by this method are of low quality [28]. Moreover, additional steps are then required for the integration of the drugs [29]. The thermal degradation method provides the best solution in terms of physicochemical properties (size, size dispersion, crystallinity, reproducibility) of the iron oxide cores but yields IONP only stable in organic solvent. Consequently an additional step is required for aqueous stabilization of the NP before any integration of drugs [30]. Here, we address the possibility of directly stabilizing oleic acid-coated iron oxide nanoparticles (OA-IONP) prepared by thermal degradation through micellation with the bioactive glycosides described before. In these colloidal structures, the hydrophobic alkyl glycoside tails surround the aliphatic chain of the OA-coated IONP through hydrophobic interactions, while the hydrophilic sugar is distributed on the outer surface of the micelle, thus improving water-dispersibility by covering the hydrophobic layer. This configuration where the therapeutic cargo also functions as the micellar coating 
requires additional tests to study the viability of the drug delivery system. As a first step, it must be tested whether the bioactive coatings fulfill the requirements of the resulting hydrophilic matrix for the in vivo use of the probes (i.e., prevented opsonization, improved colloidal stability, biocompatibility, and suitable relaxometric properties for imaging applications). Then it is key to monitor whether the anti-tumor activity is preserved in the micellar formulations of these therapeutic compounds.

\section{Materials and Methods}

\subsection{Materials and General Procedures}

All chemicals for the preparation of the glycosides were of reagent grade or higher and were purchased from commercial suppliers or purified by standard techniques as described in the previously published methods. Thin-layer chromatography (TLC) was performed on aluminum sheets 60 F254 Merck silica gel, and compounds were visualized by ultraviolet (UV) irradiation or by treatment with $\mathrm{Ce}_{2} \mathrm{MoO}_{4}$ or $5 \% \mathrm{H}_{2} \mathrm{SO}_{4}$ solutions in ethanol, followed by heating. Flash column chromatography was performed using thick-walled columns filled with silica gel (Merck 60: 0.040-0.063 mm). In all cases, the eluent used is indicated, and the solvent ratios refer to volume. Mass spectrometry was performed with an Agilent 6500 Accurate Mass Q-TOF spectrometer (Santa Clara, CA, USA) with an electrospray source. The purity of all compounds was $>95 \%$ as determined by elemental analyses using a Heraus CHN-O analyzer (Cologne, Germany). All the chemicals for the preparation of the oleic acid-coated iron oxide nanoparticles OA-IONP were purchased from Sigma-Aldrich Co. (St. Louis, MO, USA).

\subsection{Synthesis}

\subsubsection{Synthesis of the Oleic Acid-Coated Iron Oxide Nanoparticles, OA-IONP}

The preparation of OA-IONP was based on a thermal degradation method we published before [7]. Briefly, to a three-neck flask was added a mixture of iron acetylacetonate $(0.71 \mathrm{~g}, 2 \mathrm{mmol})$, 1,2-hexadecanediol (2.38 g, $10 \mathrm{mmol})$, oleic acid (1.69 g, $6 \mathrm{mmol})$, oleylamine (1.60 g, $6 \mathrm{mmol})$ and phenyl ether $(20 \mathrm{~mL})$. The reaction was kept under inert atmosphere $\left(\mathrm{N}_{2}\right)$ and heated up to $200{ }^{\circ} \mathrm{C}$ with mechanical stirring. Magnetic stirring was avoided to not interfere with the magnetic properties of the iron oxide nanoparticles. Once the desired temperature stage was reached, it was kept for $120 \mathrm{~min}$. Subsequently the mixture was brought to reflux during $30 \mathrm{~min}$ at $254{ }^{\circ} \mathrm{C}$ before being cooled to room temperature (RT). After that, ethanol $(\mathrm{EtOH})$ was added and the resulting solution was centrifuged at $8500 \mathrm{rpm}$. Obtained supernatant was next discarded to remove side products. This purification step was repeated three times, and finally OA-IONP were re-dispersed in n-hexane $(20 \mathrm{~mL})$ and oleic acid $(0.05 \mathrm{~mL})$. This suspension was centrifuged at $8500 \mathrm{rpm}$ to remove aggregates and obtain the final OA-IONP colloid.

\subsubsection{Synthesis of GC22, IG20 and TFA-GC22}

The glycosides GC22, IG20, TFA-GC22 were synthesized according to previous reported procedures [16,17,31]. Briefly for GC22 (Oleyl 2-Acetamido-2-deoxy- $\alpha$-D-glucopyraroside), $N$-Acetyl-D-glucosamine $(4.32 \mathrm{~g}, 19.5 \mathrm{mmol})$ was dissolved in oleic alcohol $(85 \%)(28 \mathrm{~mL}, 76 \mathrm{mmol})$ under argon and treated with the acid catalyst $\mathrm{H}_{2} \mathrm{SO}_{4}$ adsorbed on silica (440 $\mathrm{mg}$ ). The reaction mixture was stirred at $180{ }^{\circ} \mathrm{C}$ for $1 \mathrm{~h}$. After this time, the mixture was cooled at room temperature and diluted with methanol. Then, the catalyst filtrated and compound GC22 was obtained by silica gel column chromatography Ethyl acetate-Methanol (AcOEt-MeOH) 10:0 to 10:1 as a solid (3.3 g, 36\%). Two further crystallizations afforded GC22 with higher purity (1.33 g, 14\%). For IG20 (oleyl 2-acetamido-2-deoxy-6-O-(oxosulfonyl)- $\alpha$-D-glucopyranoside potassium salt), glycoside GC22 (521 mg, $1.1 \mathrm{mmol}$ ) was dried under vacuum, dissolved in anhydrous pyridine $(1.4 \mathrm{~mL})$ and cooled to $0{ }^{\circ} \mathrm{C}$. Then, $\mathrm{SO}_{3}$-pyridine complex $(210 \mathrm{mg}, 1.32 \mathrm{mmol})$ was added and the reaction mixture was stirred under argon at $0{ }^{\circ} \mathrm{C}$ for $90 \mathrm{~min}$. Then it was stirred at room temperature for $2 \mathrm{~h}$. After 
this time, the solvent was removed on vacuum and the residue was dissolved in $\mathrm{MeOH}-\mathrm{H}_{2} \mathrm{O}$ (2:1, $25 \mathrm{~mL})$, neutralized with a $0.5 \mathrm{M} \mathrm{KOH}$ solution and concentrated in vacuum. The residue was purified by silica gel column chromatography $\left(\mathrm{CH}_{2} \mathrm{Cl}_{2} / \mathrm{MeOH}, 4: 1\right.$ to $\left.2: 1\right)$ to give IG20 as a white solid (525 mg, 81\%). For TFA-GC22 (oleyl 2-deoxy-2-trifluoroacetamido- $\alpha$-D-glucopyranoside), $N$-trifluoroacetyl-D-glucosamine $(1.18 \mathrm{~g}, 4.29 \mathrm{mmol})$, prepared as described in the literature [32], was dissolved in $85 \%(v / v)$ oleic alcohol $(\mathrm{mL}, 21.4 \mathrm{mmol})$ and treated with $35 \%(w / w) \mathrm{H}_{2} \mathrm{SO}_{4}$-silica (236 $\mathrm{mg}$ ). This mixture was stirred at $180^{\circ} \mathrm{C}$ under argon for $20 \mathrm{~min}$ (TLC: ethyl acetate). After this period, the mixture was cooled at $25{ }^{\circ} \mathrm{C}$ and purified by silica gel column chromatography (hexane-ethyl acetate, $2: 1$ to $0: 1)$ to obtain $29 \%$ yield TFA-GC22 (604 mg) as a white solid.

\subsubsection{Synthesis of Glycosides-Coated IONP Micelles GC22-IONP, IG20-IONP, TFA-GC22-IONP}

The glycosides GC22, IG20, TFA-GC22 (10 to $20 \mathrm{mg}$ dissolved in $1 \mathrm{~mL}$ of ethanol was initially dispersed in $15 \mathrm{~mL}$ of $5 \mathrm{mM}$ phosphate buffer at $\mathrm{pH}=7.2$ One milliliter of the OA-IONP suspension in hexane (with 10-15 $\mathrm{mg} \cdot \mathrm{mL}^{-1}$ iron concentration) was then added to the solution and the resultant mixture was sonicated for $20 \mathrm{~min}$ at $37{ }^{\circ} \mathrm{C}$ under robust stirring (Branson 250 digital Ultranofier, $42 \pm 6 \mathrm{KHz}$, Danbury, CT, USA). The resultant oil in water (o/w) emulsion was for an additional $1 \mathrm{~h}$ sonication to remove all traces of hexane and ethanol resulting in a homogenous micellar aqueous suspension. Aggregates were filtrated $(0.22 \mu \mathrm{m}$, polyvinylidene difluoride membrane) and the excess of free glycoside eliminated by gel filtration in a PD-10 column (GE Healthcare, Milwaukee, WI, USA).

\subsection{Physicochemical Characterization of the Oleic Acid-Coated IONP (OA-IONP) and the Glycosides-Coated IONP Micelles GC22-IONP, IG20-IONP, TFA-GC22-IONP}

Zetasizer Nano ZS90 (Malvern Instruments, Malvern, UK) was used to measure the hydrodynamic size, polydispersity index and zeta potential of the IONP micelles. JEOL-3000 (FXII, 300-keV, Akishima, Tokio, Japan) was used to determine the shape and size of the IONP cores. Samples were prepared as follows, a drop of glycoside-coated IONP micelles diluted solution was put on a carbon-coated grid and dried at RT for one day. Spectrum 400 Series spectrometer (Perkin Elmer, Waltham, MA, USA) was used to obtain the Fourier transformed infrared spectroscopy (FTIR) spectra from the average of 32 interferograms at a $1 \mathrm{~cm}^{-1}$ resolution. TG/ATD $320 \mathrm{U}$, SSC 5200 (Seiko Instruments, Minato, Tokio, Japan) was used for thermogravimetric analysis (TGA) The dried IONP micelles were heated from RT to $1000{ }^{\circ} \mathrm{C}$ at a rate of $10{ }^{\circ} \mathrm{C}$ per min and under an airflow of $100 \mathrm{~mL} \cdot \mathrm{min}^{-1}$. Bruker Esquire 3000 apparatus (Bruker Daltonik, Billerica, MA, USA) equipped with an electrospray ionization source plus an ion trap analyzer; and coupled to an Agilent 1100 capillary Liquid-Chromatography (LC) system (Agilent Technologies, Santa Clara, CA, USA) was used to perform mass spectrometry. The sample was diluted in water/methanol (1:1) solution and the analysis were carried out by FIA (flow injection analysis) with a $0.1 \%$ formic acid/methanol $(1 / 1)$ eluent at a rate flow of $0.1 \mathrm{~mL} \cdot \mathrm{min}^{-1}$.

\subsection{Magnetic Characterization of the Oleic Acid-Coated IONP (OA-IONP) and the Glycosides-Coated IONP Micelles GC22-IONP, IG20-IONP, TFA-GC22-IONP}

Magnetic characterization of the samples was carried out in a vibrating sample magnetometer using $100 \mu \mathrm{L}$ of solution in a special sample holder. Magnetization curves were recorded at room temperature by first saturating the sample in a field of $1 \mathrm{~T}$. The magnetization values were normalized to the amount of iron to yield the specific magnetization (emu/g Fe). The initial susceptibility of the suspensions was measured in the field range $\pm 100 \mathrm{Oe}$, and the saturation magnetization values (Ms) were evaluated by extrapolating to infinite field the experimental results obtained in the high field range where the magnetization linearly increases with $1 / \mathrm{H}$. For determination of the Nuclear Magnetic Resonance (NMR) relaxometric values, the T2 and T1 relaxation times were measured at $37^{\circ} \mathrm{C}$ in a Bruker MQ60 (Bruker Biospin, Germany) operating at 1.5 Tesla with a T2 Carr-Purcell Meiboom Gill and T1 Inversion-Recovery spin echo pulse sequences. The relaxation rate $R_{\mathrm{i}}\left(1 / T_{\mathrm{i}}, i=1,2\right)$ values, obtained from the measured relaxation times $\left(T_{\mathrm{i}}, \mathrm{s}\right)$ were corrected by subtracting the relaxation rate of 
the water used to prepare the contrast agent. Linear fitting of the data and resulting slopes provide the relaxivities $\left(\mathrm{r}_{\mathrm{i}}, \mathrm{s}^{-1} \cdot \mathrm{mM}^{-1}\right)$ values related to the iron concentration $(\mathrm{mM}): R_{\mathrm{i}}=R b_{\mathrm{i}}+\mathrm{r}_{\mathrm{i}}[\mathrm{Fe}]$.

\subsection{In Vitro Activity of the Glycosides-Coated IONP Micelles, Inhibition of A549 and C6 Tumor Cell Proliferation}

Human A549 and C6 rat glioma cell lines were maintained at $37{ }^{\circ} \mathrm{C}$ and $5 \% \mathrm{CO}_{2}$ humidified atmosphere in Dulbecco's modified Eagle's medium (DMEM) (Sigma-Aldrich, St. Louis, MO, USA) supplemented with fetal bovine serum (FBS, 10\%; GLinus, Madrid, Spain), glutamine (2 mM), penicillin (50 IU/mL), and streptomycin $(50 \mathrm{mg} / \mathrm{mL})$. Cells were seeded on 96-well plates (Beckton Dickinson, Le Pont de Claix, France), in DMEM complete medium, at a density of, respectively, $1.5 \times 10^{4}$ cells $/$ well for C6 and with $5 \times 10^{3}$ cells/well for A549 cells. These exponentially growing cells were left to attach in some conditions and then, the medium was replaced with $100 \mu \mathrm{L}$ of fresh DMEM without FBS and maintained overnight. Stock solutions in $50 \mathrm{mM}$ ethanol of the free glycosides (GC22, IG20, TFA-GC22) or stock phosphate buffered saline (PBS) solutions of the glycosides-coated IONP micelles (GC22-IONP, IG20-IONP, TFA-GC22-IONP) were finally dispersed in DMEM complete medium for the different treatments. The cells were treated with serial dilutions ( 2 to $400 \mu \mathrm{M}$ ) of glycoside derivatives (final ethanol concentration $<0.8 \%$ ), micelles or control vehicles (PBS) for $48 \mathrm{~h}$. For the experiments with micelles, several 96-well plates were placed over a strong magnetic field provided by a Magneto FACTOR-96 (Chemicell) to increase the proximity of the nanoparticles to the cells. Similarly to previous described work [33], azelaic acid-coated IONP (Az-IONP) were tested as negative control. Cell proliferation was evaluated with a 3-(4,5-dimethyltiiazol-2-yl)-2,5-diphenyltetrazolium bromide (MTT) assay (Sigma-Aldrich). For this test, after $48 \mathrm{~h}$ treatment with each compound, the medium was replaced by $100 \mu \mathrm{L}$ of fresh DMEM without phenol red containing $5 \mathrm{mg} / \mathrm{mL}$ MTT solution, and the cells incubated at $37^{\circ} \mathrm{C}$ with $5 \% \mathrm{CO}_{2}$ for additional $3 \mathrm{~h}$. After this step, the medium was removed, and the resulting insoluble product of this assay precipitated as formazan was dissolved in $100 \mu \mathrm{L}$ of DMSO, and the optical density of the solution was measured in a Spectramax Plus equipment (Molecular Devices Corporation, San José, CA, USA) at $595 \mathrm{~nm}$. Three independent experiments were performed with each compound tested in triplicates. The formula used to calculate the percentage of proliferation inhibition was:

$$
\% \text { inhibition }=100-100[(X-B) /(A-B)]
$$

where $\mathrm{A}$ is the formazan produced by cells maintained in DMEM complete medium (high mitosis control), B is the produced by cells in DMEM without FBS (low mitosis control), and X represents the optical density of cells treated with test inhibitors. Dose response plots of percent inhibition versus concentration were adjusted to sigmoidal curves from which $\mathrm{IC}_{50}$ values were calculated using Graph Pad Prism 5.0 software. Using this formula, 100\% inhibition means that the treated cells produced the same formazan as the cells in DMEM without FBS (low mitosis control). If the percentage is higher than $100 \%$ means that the cells are dying.

\section{Results}

\subsection{Synthesis of Glycosides-Coated IONP Micelles}

OA-IONP were synthetized at high temperature by thermal degradation of iron organic precursors blended with the OA surfactant. The resulting OA-IONP colloidal solution in hexane was stable and monodisperse, with a 0.25 polydispersity index and a $10 \pm 3 \mathrm{~nm}$ mean hydrodynamic size; also, iron oxide cores were spherical with a diameter of $7 \pm 2 \mathrm{~nm}$ determined by TEM (Figure 1a). These values are comparable to previously reported IONP prepared with similar synthesis and confirmed the high control on size and uniformity of the particles provided by thermal degradation method [34,35]. The crystalline structure of the iron oxide cores was determined by X-ray diffraction (XRD) and the pattern corresponded to a magnetite phase (Powder Diffraction File Card No. 16-0629; Supplementary 
Figure S1a). Surfactant coating was further characterized by Fourier Transformed Infrared spectroscopy (FTIR). The spectrum displayed the vibration peaks characteristic of both, the magnetite core and the OA surfactant (Figure S1b) [36]. For the magnetite core, the band typical of the Fe-O bound in crystalline structure was seen at $590 \mathrm{~cm}^{-1}$. For OA, (va C-H) and (vs C-H) corresponding to the aliphatic moieties appeared respectively at $2920 \mathrm{~cm}^{-1}$ and $2850 \mathrm{~cm}^{-1}$, and the vibrations corresponding to the carboxylic group ( $\vee \mathrm{C}-\mathrm{O}$ ) were found at $1625 \mathrm{~cm}^{-1}$ and $1530 \mathrm{~cm}^{-1}$. These last peaks also give an indication about the kind of coordination of the surfactant with the iron oxide cores. Indeed, wavelengths were higher than the typical $\mathrm{C}-\mathrm{O}$ band but lower than the $\mathrm{C}=\mathrm{O}$ one, and additionally the differences represented less than $110 \mathrm{~cm}^{-1}$. This suggest that the carboxyl is coordinated via a bidentate complex between the two oxygen and the iron atoms at the core surface. Thermogravimetric analysis (TGA) was also performed to evaluate the graft density of the organic coating. As shown in Figure S1c, the weight loss between 190 and $300{ }^{\circ} \mathrm{C}$ corresponded the OA removal. This accounted for $15 \%$ of the total weight of the nanoparticles.

\section{(a)}

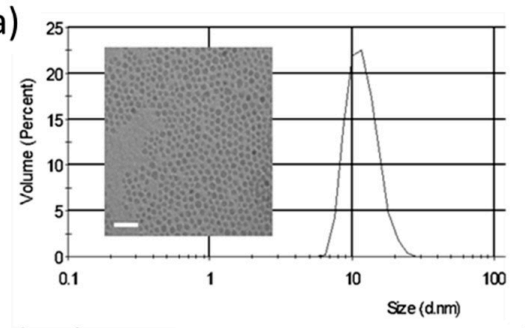

(b)

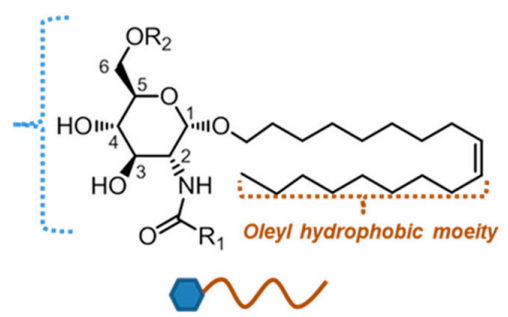

$1 \mathrm{GC} 22=\mathrm{R}_{1}-\mathrm{CH}_{3} \quad \mathrm{R}_{2}-\mathrm{H}$

$2 \mathrm{IG} 20=\mathrm{R}_{1}-\mathrm{CH}_{3} \quad \mathrm{R}_{2}-\mathrm{SO}_{3} \mathrm{~K}$

3 TFA-GC22 = $\begin{array}{ll}\mathrm{R}_{1}-\mathrm{CF}_{3} & \mathrm{R}_{2}-\mathrm{H}\end{array}$

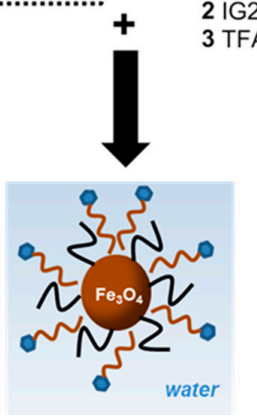

Figure 1. Scheme of the synthesis of the glycosides-coated IONP micelles. (a) Hydrodynamic size and TEM image (scale bar: $25 \mathrm{~nm}$ ) of OA-IONP; (b) Structure of the bioactive glycosides.

Finally, one of the most important properties of the iron oxide nanoparticles that bio-applications, especially MRI, take advantage of is their magnetism. It was measured using a vibrating sample magnetometer (VSM) and OA-IONP displayed a superparamagnetism behavior with a high saturation magnetization value Ms of $70 \mathrm{emu} \cdot \mathrm{g}^{-1}$ (Supplementary Figure S1d). This is a typical feature of the IONP prepared by thermal degradation methods that produce highly crystalline cores, compared to the aqueous co-precipitation method that produce IONP of lower saturation magnetization. This difference is particularly appreciable in the case of magnetic guidance bio-applications, where high Ms values strongly support the efficiency of magnetic attraction [15,37].

Fernández-Mayoralas et al. described a family of synthetic glycoside derivatives as inhibitors of glioma and adenocarcinoma growth, of which we selected three compounds for the preparation of OA-IONP encapsulated anti-tumor micelles (Figure 1b) [16]. In all cases, the bioactive glycosides have an oleyl chain moiety with $\alpha$ anomeric configuration of the glucosamine scaffold, described as optimal for antitumoral activity [24]. The antimitotic activities of GC22, IG20, TFA-GC22 against C6 (rat glioma line) and A549 (human lung adenocarcinoma line) are described in Table 1. GC22-taken as reference-presented an $\mathrm{IC}_{50}$ in the micromolar range for both cell lines. The influence of a different 
amide group $\left(\mathrm{R}_{1}\right)$ at position $\mathrm{C}-2$ (trifluoroacetamide, TFA-GC22) and the change caused by attachment of a negative hydrophilic oxosulfonyl group at C-6 position $\left(\mathrm{R}_{2}\right)$ in IG20 were studied. Although the trifluoroacetamide group did not seem to affect much the antimitotic activity, the presence of the oxosulfonyl group had a deleterious effect on the bioactivity, with $\mathrm{IC}_{50}$ ten times higher, $>100 \mu \mathrm{M}$. A more detailed information of the effects of the substituted groups on the glucosamine backbone on the inhibition of cancerous cell lines can be found in previous reports [17]. The chemistry for the preparations of the derivatives is well-known in the field and synthetic procedures can be obtained in previous publications $[16,17,31]$.

Table 1. Comparison of the $\mathrm{IC}_{50}$ of the free glycosides and the glycosides-coated IONP micelles. w/o: without magnet; w/: with magnet.

\begin{tabular}{ccc}
\hline Compound & IC $_{\mathbf{5 0}}(\boldsymbol{\mu M})$ & $\mathrm{IC}_{\mathbf{5 0}}(\boldsymbol{\mu M})$ \\
& $\mathbf{C 6}$ & $\mathbf{A 5 4 9}$ \\
\hline GC22 & $15.5 \pm 0.3$ & 10 \\
GC22-IONP w/o magnet & 55.0 & 100.5 \\
GC22-IONP w/ magnet & 70.0 & 95.0 \\
\hline IG20 & $>100$ & 97 \\
IG20-IONP w/o magnet & 68.5 & 64.4 \\
IG20-IONP w/ magnet & 57.2 & 91.0 \\
\hline TFA-GC22 & $14.2 \pm 0.3$ & 8.6 \\
TFA-GC22-IONP w/o magnet & 24.4 & 40.3 \\
TFA-GC22-IONP w/ magnet & 49.8 & 42.0 \\
\hline
\end{tabular}

In brief, GC22 was obtained by Fischer-type glycosidation of N-acetyl-D-glucosamine (1) with oleyl alcohol. IG20 was prepared in a single step by regioselective sulfation of GC22 using $\mathrm{SO}_{3}$-pyridine complex in $81 \%$ yield. For the synthesis of TFA-GC22, D-glucosamine (2) was subjected to $\mathrm{N}$-trifluoroacetylation followed by glycosylation with oleyl alcohol via $\mathrm{H}_{2} \mathrm{SO}_{4}$-silica catalyzation (Figure 2).

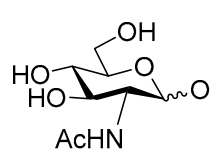

1
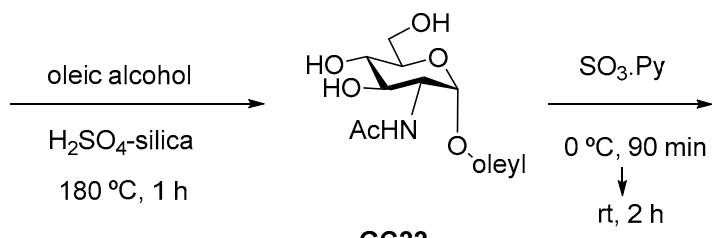

GC22
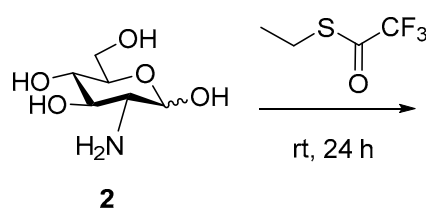

$\mathrm{rt}, 24 \mathrm{~h}$

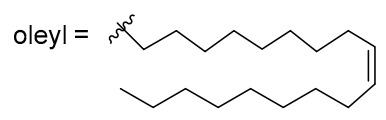

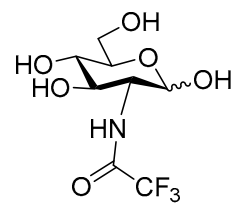

3

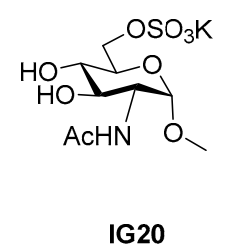

IG20

Figure 2. Synthesis of the glycosides GC22, IG20, TFA-GC22.

The hydrophobic OA-IONP were then encapsulated following a nanoemulsion method already reported [38], as micelles made of the oleyl glycosides to obtain GC22-IONP, IG20-IONP and 
TFA-GC22-IONP, respectively. In this process, the oleyl moiety of the glycoside intercalates with the OA aliphatic chain of the magnetite core through hydrophobic van der Waals interactions while the hydrophilic sugar counterpart covering the outer side provides the required water stability as illustrated in Figure 1 [38]. The resulting nanostructure was defined as co-dependent because such as the OA-IONP, the glycosides-except IG20-were not soluble in water and only when pairing them led to the final hydrophilic micellar suspensions. OA-IONP, in this sense, simultaneously acted as scaffold and as micelle promoter since the free glycosides did not form spontaneous micelles.

\subsection{Physicochemical Characterization of the Glycosides-Coated IONP Micelles}

The hydrodynamic sizes of the micelles were in the $50 \mathrm{~nm}$ range of (Table 2) with pdi below 0.25 , the standard level to be considered as a monodisperse population. TEM results confirmed that the NPs were well-dispersed with no aggregation (Figure 3a). However, the increase in hydrodynamic micellar sizes probably indicates the encapsulation of a few OA-IONP within the same micelle or a slight aggregation in solution of different micelles. The absolute values of zeta potential were in all cases above $25 \mathrm{mV}$ at $7.4 \mathrm{pH}$ (Table 2), indicating a good stability of the micellar colloidal dispersions by electrostatic repulsion. GC22-IONP micelles show a $\zeta$ potential around $-25 \mathrm{mV}$ attributable to the glucosamine layer. IG20-IONP micelles had a higher negative $-50 \mathrm{mV} \zeta$ potential because of the additional presence of the negatively charged oxosulfonyl group on the glucosaminic scaffold. Surprisingly TFA-GC22-IONP micelles had a positive $\zeta$ which might be explained by the de-acetylation and formation of a positive amine group at $\mathrm{C} 2$ during the nanoemulsion process. Fourier Transformed Infrared (FTIR) spectra of the micelles (Figure 3b) confirmed the presence of the sugars on the outer layer. The vibration of the oleyl glucosamides were observed at 620,2920 and $1700 \mathrm{~cm}^{-1}$, in addition to the peaks characteristic of OA-IONP (for instance the stretching band at $590 \mathrm{~cm}^{-1}$ for the $\mathrm{Fe}-\mathrm{O}$ bound of the inorganic crystalline core structure). Partial formation of the amine derivative of TFA-GC22 in the coating of the TFA-GC22-IONP micelle was also verified, FTIR spectra showing a strong absorption band at $3400 \mathrm{~cm}^{-1}$, corresponding to the primary amine vibration $\left(\vee \mathrm{C}-\mathrm{NH}_{2}\right)$. This was also confirmed by the molecular weight of the adduct of the glucosamine de-acetylated detected by mass spectroscopy (MS) (Supplementary Figure S2).

(a)

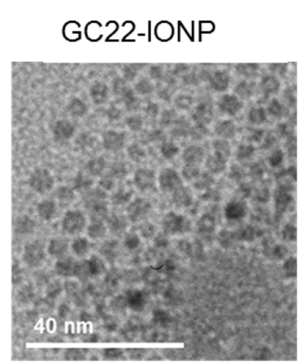

IG20-IONP

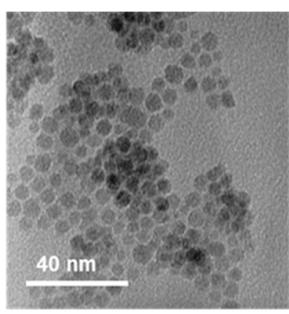

TFA-GC22-IONP

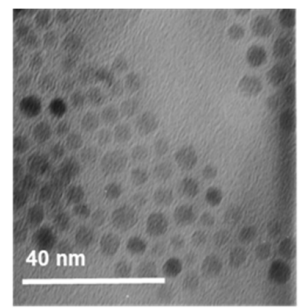

(b)

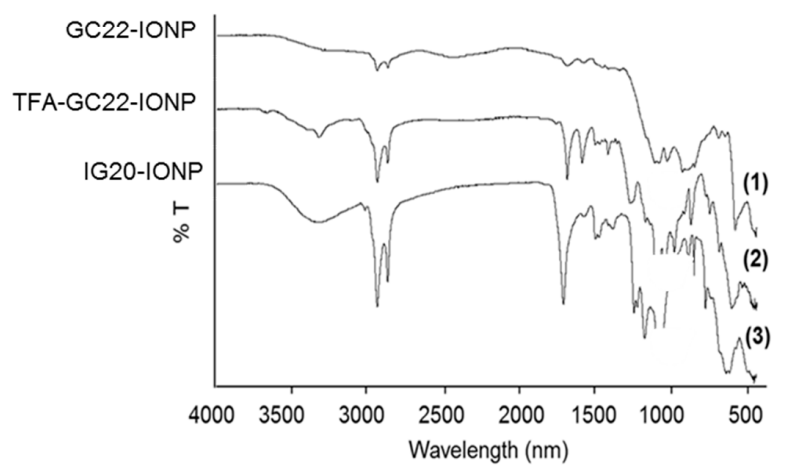

Figure 3. Characterization of the glycosides-coated IONP. (a) TEM images and (b) FTIR spectra of the three glycoside-coated IONP. 
The magnetic and relaxation properties of IONP micelles are important features for their applications as magnetically delivered drug platforms and as MRI contrast agents. The NMR relaxometric properties at $1.5 \mathrm{~T}$ and $37^{\circ} \mathrm{C}$ were then investigated, and the longitudinal and transverse relaxivities $\left(r_{1}, r_{2}\right.$, respectively) calculated in water suspensions. The results were similar for each micelle with high $r_{2}$ (from 140 to $200 \mathrm{~s}^{-1} \cdot \mathrm{mM}^{-1}$ ) and small $r_{1}$ (below $4.5 \mathrm{~s}^{-1} \cdot \mathrm{mM}^{-1}$ ); values particularly appropriate for $\mathrm{T}_{2}$-weighted MRI-based contrast agents (Table 1) [39].

Table 2. Main physicochemical characteristics of the glycosidic IONP micelles.

\begin{tabular}{ccccccc}
\hline $\begin{array}{c}\text { Glycosidic } \\
\text { IONP Micelles }\end{array}$ & $\begin{array}{c}\text { Size } \\
(\mathbf{n m})\end{array}$ & Pdi & $\begin{array}{c}\text { Zeta Potential } \\
(\mathbf{m V})\end{array}$ & $\begin{array}{c}{[\mathrm{Fe}]} \\
(\mathbf{m g} / \mathbf{m L})\end{array}$ & $\begin{array}{c}\mathbf{C}^{\circ} \text { [glyco] } \\
(\mathbf{m g} / \mathbf{m L})\end{array}$ & $\begin{array}{c}\text { Relaxometric Parameters } \\
\left(\mathbf{s}^{-\mathbf{1}} \cdot \mathbf{m M}^{-1}\right)\end{array}$ \\
\hline GC22-IONP & 40.5 & 0.24 & -27 & 0.6 & 2.5 & $\begin{array}{r}r_{1} 2.7 \\
r_{2} 140\end{array}$ \\
\hline IG20-IONP & 52.2 & 0.15 & -42 & 1.1 & 3.1 & $\begin{array}{r}r_{1} 4.4 \\
r_{2} 195\end{array}$ \\
\hline TFA-GC22-IONP & 49.1 & 0.17 & +53 & 0.3 & 2.5 & $r_{1} 3.6$ \\
\hline
\end{tabular}

\subsection{In Vitro Antitumoral Activities of the Glycosides-Coated IONP Micelles}

We assessed whether the glycosides under IONP-based micellar formulation have preserved their antimitotic activity for $\mathrm{C} 6$ rat glioma and A549 human lung carcinoma cells in culture. GC22-IONP, IG20-IONP and TFA-GC22-IONP were synthesized with a final amount from 2.5 to $3.5 \mathrm{mg} \cdot \mathrm{mL}^{-1}$ of these molecules in the micellar formulation. To calculate the concentration of the glycosides in the colloidal dispersion, lyophilized micelles were partitioned by sonication in a water/ethanol mixture. After centrifugation, supernatants containing the free glycosides were quantified by high performance liquid chromatography (Table 2).

The cells were treated with dilutions of the micelle solution and cell growth was evaluated after $48 \mathrm{~h}$ incubation by MTT assays. Control NP consisted of OA-IONP that underwent an oxidative treatment to get azelaic acid-coated IONP (Az-IONP), stable in water [40]. The inhibitory activities of the micelles and the control on rat glioma and lung carcinoma cells with respect to the molar concentration of the free glycosides are shown respectively in Supplementary Figure S3 and S4. These inhibitory activities were also determined in the presence of a magnetic field placed outside the bottom of each well in the plate. The results for the $50 \%$ inhibitory dose values $\left(\mathrm{IC}_{50}\right)$ compared to the $\mathrm{IC}_{50}$ for the free glycosides were summarized in Table 1.

All the glycoside-coated IONP micelles inhibited proliferation of the both cancer cell lines with $\mathrm{IC}_{50}$ in the micromolar range while control Az-IONP did not displayed any inhibition activity. In general, the inhibitory concentration for all micellar preparations was within the same range but slightly higher as the corresponding free glycoside used in the formulation. As an exception to this pattern, IG20-IONP had higher inhibitory activity in micellar form than as a free glycoside. In fact, the free IG20 glycoside did not have any inhibitory activity in C6 cell line at the highest concentration tested $(100 \mu \mathrm{M})$. Among the micellar preparation, the greatest antimitotic activity was obtained for TFA-GC22-IONP (with a fraction of amine derivatives in the coating) on rat glioma cells. As control, the inhibitory activity of the free amine derivative of TFA-GC22 was also assessed and gave similar results than its parent compound. It can also be seen that when the biological activities were determined in the presence of a magnetic field, the results were similar or worse. This may be explained because the magnet immediately attracts the NP to the center of the plate so they cannot disperse over the whole plate. 


\section{Discussion}

We have synthesized a variety of theranostic micelles formed by OA-IONP stabilized in water by a coating made of different antitumoral oleyl glycosides. These original nanoparticles were originally prepared at high temperature by thermal degradation of organic iron precursors resulting in iron oxide cores with higher quality to those obtained by hydrolytic routes as suggested by previous studies [9,41], and ready to be used as contrast agent and magnetically driven carrier. Three oleyl derivative glycosides previously reported as antitumoral agents $[16,17]$ were then used to create amphiphilic structures where the oleic acid surfactant of the NP and oleyl moiety of the sugars associated as a Van der Walls interaction pair, while the hydrophilic part of the glycoside stood in the outer layer for aqueous stabilization. We obtained this micellar-like structure by spontaneous arrangement of the two moieties using a nanoemulsion procedure [38]. This approach is currently used for synthesis of other NP-based amphiphilic assemblies as it speeds up and simplified this preparation and provides reproducible and highly uniformed dispersion especially when compared to the reverse evaporation method highly extended in the field [42].

Our drug delivery approach is different from normal controlled drug delivery systems (e.g., liposomal or polymeric NP), in which the drug is usually incorporated by encapsulation in a carrier vehicle or by ionic or covalent bindings onto a prior hydrophilic NP coating [27]. This formulation facilitates the diffusion and releasing of the drug by passive transport or enzymatic cleavage once the NP has reached to the site of therapeutic interest. Additional active functionalization with peptides, proteins or antibodies lead to enhanced targeting multifunctional formulations for a very efficient delivery [11]. Here, the addition of an active targeting ligand on these peculiar micelles is a synthetic challenge. The main aspect of our solution lies in the fact that the stabilizing and biocompatible coating of the NP is the own active component of the drug, and therefore should maintain its therapeutic efficiency. For this reason, we verified that the antitumoral activity was fully preserved upon the micelle formation. The presence of an oleyl aglycon group on the glycosides was described as the most positive factor for cancerous cell growth inhibition. Based on our previous work, the effect of these glycosides seems to be the result of their interaction with the cell membranes. It was previously shown that GC22 and TFA-GC22 act altering the sphingolipid metabolism of cancer cells [20] by activating neutral sphingomyelinase at the cell membrane [17]. In another work, we showed that the fluorescent derivative of IG20 was predominantly located in the membrane of chromaffin cells [43]. In these OA-IONP-based glycosidic micelles, the aliphatic chain is shielded by the amphiphilic nanoassembly. Of notice, although this could also proceed against our own interest, bioactivity was preserved and in the IG20-IONP case was even higher than the one of the free molecules. This may indicate that even under a micellar form, the bioactive glycosides can intercalate in the lipid bilayer of the cell membrane. If for the free glycosides, a higher hydrophilicity is inclined to reduce the antimitotic activity for the both, $\mathrm{C} 6$ and $\mathrm{A} 549$ cancer cell lines $\left(\mathrm{IC}_{50}\right.$ values were much higher for the only water-soluble glycoside IG20, while GC-22 and TFA-GC22 presented good and almost similar inhibitory activities), the opposite effect was observed when glycosides are under micellar form. Indeed, inhibition of cell proliferation by IG20-IONP got a significant increase and the activities of TFA-GC-22-IONP (considering the partial formation of the hydrophilic amine derivative) were relatively better preserved than the GC22-IONP ones. Therefore, it could be the case that the micellar state of IG20 in the NP could enable the intercalation of IG20 in the membrane, similarly to some amphiphilic surface active drugs, thus facilitating its biological activity [44]. Besides, the free oleyl glycosides were successfully used in vivo bound to the BSA protein, a fatty acid transporter which plays a role similar to that played by the micelles described here [24].

One of the main challenges of anti-cancer chemotherapy is that it might affect both tumor and healthy tissues. The optimal solution will be synthesizing drugs specifically addressed against cancerous cells taking advantage of the differences between the tumor and normal cell biological pathways [45]. New specific targeting strategies including drug delivery platforms (either biological such as targeting organic ligands, or physical such as magnetically guided NP) start to provide different 
alternatives. In the present work, oleyl glycosides act on the activated lipid synthesis pathways of tumor cells, that require cell membrane products to sustain transformed cell proliferation [19]. This first selective characteristic, combined with other properties of the IONP-based drug delivery platform, such as a possible EPR effect enhancing the accumulation of NP in tumors, magnetic-guided delivery, or hyperthermia applications, can be a strong support point for an in vivo chemotherapy with high specificity for the modified cells. On this regard, EPR effects shall be facilitated by the $50 \mathrm{~nm}$ size of the micelles, particularly adapted for an easy accumulation or diffusion through increased vascular permeability often accompanying pathological processes [46] and also by the long enough circulation times in the same order those described for IONP of similar hydrodynamic sizes [47]. This contributes to increase the chances of higher micellar accumulation and to provide a local optimal inhibitory concentration for the glycosides. In the same way, a previous evaluation of the free glycosides in vivo showed that contributors to a low efficiency of the treatment were both, the low aqueous solubility of the compounds together with their degradation by activated macrophage enzymes (i.e., hexosaminidases) present in the inflamed tumor area, that can cleave the glycoside bonds and inactivate the inhibitor [24]. Therefore, it would be of great interest to study whether glycosides under the micellar form could cultivate an enzymatic resistance toward hexosaminidases degradation, contributing as well to higher efficiency of the antitumoral activity. Lastly, it is important to point out the concern about potential toxicity of iron oxide nanoparticles-based therapeutics still under debate, and that may limit their use in vivo. Although many of the first developed IONP contrast agents have been withdrawn from the market because of their low benefice-to-risk balance, a new generation of iron oxide formulations is on the market or under phase III clinical trials either for medical imaging or therapy, particularly fueled by hyperthermia and lymph node detections $[48,49]$. The perspective of translational research for the next decade is quite optimistic if lessons from the previous uses are learned and toxicity assessments are performed on case-by-case basis [50,51]. Regarding the specific IONP-based micellar structures, toxicity data are still limited and only available from pre-clinical studies, suggesting similar behavior for glycoside-coated IONP micelles [38,42,52].

\section{Conclusions}

It is widely known in the anti-cancer therapeutic field that glycosides attached to long oleyl hydrophobic chains show antimitotic activity on different cancerous cell lines. The delivery of these small molecules to the tumor site is difficult due to both their poor solubility and their susceptibility to in vivo enzymatic degradation. We have presented in this work a new nanoparticle-based micellar formulation for drug delivery in which these antimitotic molecules are used to stabilize oleic acid-coated iron oxide nanoparticles. These micelles showed high aqueous solubility, while retaining bioactivity when assessed against glioma C6 and carcinoma A549 cell lines. For theranostic applications, we showed that these micellar agents are also suitable as MRI contrast agents, grounded in the IONP magnetic properties. Taking all these results together, new opportunities for the therapeutic use of anti-tumor oleyl glycoside are open with extended in vivo applications, such as MRI-based diagnoses or magnetic-guided delivery. Further in vivo studies are needed to validate the pharmacological potential of these micellar candidates, in particular pharmacokinetics experiments. Finally, our study also contribute to the widespread development of nano-formulations in which the stabilizing coating and therapeutic function should go hand in hand.

\section{Patents}

Patent EP 2921179 A1 is resulting from the work reported in this manuscript.

Supplementary Materials: The following are available online at http:/ /www.mdpi.com/2079-4991/8/8/567/s1, Figure S1: Characterization of the oleic acid-coated IONP (OA-IONP). Figure S2: Mass spectra of TFA-GC22-IONP performed in positive ionization. Figure S3: Inhibitory activities of the free glycosides and the glycosides-coated IONP micelles with respect to their inhibitory concentration (molar concentration) for rat glioma cells (C6) after $48 \mathrm{~h}$ incubation with or without (w/o) the support of a magnetic field placed at the bottom of the plate. Figure S4: Inhibitory activities of the free glycosides and the glycoside-coated IONP micelles with respect to their inhibitory 
concentration (molar concentration) for lung carcinoma cells (A549) after $48 \mathrm{~h}$ incubation with or without (w/o) the support of a magnetic field placed at the bottom of the plate.

Author Contributions: Conceptualization, H.G., I.G.-Á., F.H., A.F.-M. and J.R.-C.; Data curation, H.G., I.G.-Á. and L.R.-R.; Formal analysis, H.G., I.G.-Á., L.R.-R. and J.R.-C.; Funding acquisition, A.F.-M. and J.R.-C.; Investigation, H.G., I.G.-Á. and L.R.-R.; Methodology, H.G., I.G.-Á. and L.R.-R.; Project administration, J.R.-C.; Resources, A.F.-M. and J.R.-C.; Supervision, F.H., A.F.-M. and J.R.-C.; Validation, M.N.-S., F.H., A.F.-M. and J.R.-C.; Writing-original draft, H.G.; Writing-review \& editing, I.G.-Á., L.R.-R., M.N.-S., F.H., A.F.-M. and J.R.-C.

Funding: This research was funded by FP7 Marie Curie Pulmonary imaging network (PINET) and Ministerio de Economia y Competitividad MAT2015-65184-C2-2-R; SAF2016-79593-P; SAF2017-84494-C2-1-R). This work was partially funded by Instituto de Salud Carlos III (DTS16/00059), CNIC (Centro Nacional de Investigaciones Cardiovasculares), and Comunidad de Madrid (B2017-BMD3731 and B2017-BMD3875). We thank Ligue contre le cancer, comité Charentes Maritimes which allows to free up some time to complete the redaction of this manuscript during a grant-not dedicated on this work-agreed to LIENSs, UMR CNRS 7266, La Rochelle.

Acknowledgments: We thank M. P. Morales (ICMM-CSIC) for VSM measurements and TGA analysis and María Martínez-Alcazar (University CEU San Pablo) for mass spectrometry. We thank the technical platform "Centro Nacional de microscopia de la Universidad Complutense de Madrid" for the TEM experiments.

Conflicts of Interest: The authors declare no conflict of interest.

\section{References}

1. Ferrari, M. Cancer nanotechnology: Opportunities and challenges. Nat. Rev. Cancer 2005, 5, $161-171$. [CrossRef] [PubMed]

2. Gupta, A.K.; Gupta, M. Synthesis and surface engineering of iron oxide nanoparticles for biomedical applications. Biomaterials 2005, 26, 3995-4021. [CrossRef] [PubMed]

3. Cho, K.; Wang, X.; Nie, S.; Chen, Z.; Shin, D.M. Therapeutic Nanoparticles for Drug Delivery in Cancer. Clin. Cancer Res. 2008, 14, 1310-1316. [CrossRef] [PubMed]

4. Mccarthy, J.; Weissleder, R. Multifunctional magnetic nanoparticles for targeted imaging and therapy. Adv. Drug Deliv. Rev. 2008, 60, 1241-1251. [CrossRef] [PubMed]

5. Veiseh, O.; Gunn, J.W.; Zhang, M. Design and fabrication of magnetic nanoparticles for targeted drug delivery and imaging. Adv. Drug Deliv. Rev. 2010, 62, 284-304. [CrossRef] [PubMed]

6. Maeda, H.; Wu, J.; Sawa, T.; Matsumura, Y.; Hori, K. Tumor vascular permeability and the EPR effect in macromolecular therapeutics: A review. J. Control. Release 2000, 65, 271-284. [CrossRef]

7. Alexis, F.; Pridgen, E.; Molnar, L.K.; Farokhzad, O.C. Factors Affecting the Clearance and Biodistribution of Polymeric Nanoparticles. Mol. Pharm. 2008, 5, 505-515. [CrossRef] [PubMed]

8. Emerich, D.F.; Thanos, C.G. The pinpoint promise of nanoparticle-based drug delivery and molecular diagnosis. Biomol. Eng. 2006, 23, 171-184. [CrossRef] [PubMed]

9. Arruebo, M.; Fernández-Pacheco, R.; Ibarra, M.R.; Santamaría, J. Magnetic nanoparticles for drug delivery. Nano Today 2007, 2, 22-32. [CrossRef]

10. Alexiou, C.; Schmid, R.J.; Jurgons, R.; Kremer, M.; Wanner, G.; Bergemann, C.; Huenges, E.; Nawroth, T.; Arnold, W.; Parak, F.G. Targeting cancer cells: Magnetic nanoparticles as drug carriers. Eur. Biophys. J. 2006, 35, 446-450. [CrossRef] [PubMed]

11. Brigger, I.; Dubernet, C.; Couvreur, P. Nanoparticles in cancer therapy and diagnosis. Adv. Drug Deliv. Rev. 2002, 54, 631-651. [CrossRef]

12. Janib, S.M.; Moses, A.S.; MacKay, J.A. Imaging and drug delivery using theranostic nanoparticles. Adv. Drug Deliv. Rev. 2010, 62, 1052-1063. [CrossRef] [PubMed]

13. Lübbe, A.S.; Bergemann, C.; Huhnt, W.; Fricke, T.; Riess, H.; Brock, J.W.; Huhn, D. Preclinical experiences with magnetic drug targeting: Tolerance and efficacy. Cancer Res. 1996, 56, 4694-4701. [PubMed]

14. Lübbe, A.S.; Bergemann, C.; Riess, H.; Schriever, F.; Reichardt, P.; Possinger, K.; Matthias, M.; Dörken, B.; Herrmann, F.; Gürtler, R.; et al. Clinical experiences with magnetic drug targeting: A phase I study with 4'-epidoxorubicin in 14 patients with advanced solid tumors. Cancer Res. 1996, 56, 4686-4693. [PubMed]

15. Lee, N.; Yoo, D.; Ling, D.; Cho, M.H.; Hyeon, T.; Cheon, J. Iron Oxide Based Nanoparticles for Multimodal Imaging and Magnetoresponsive Therapy. Chem. Rev. 2015, 115, 10637-10689. [CrossRef] [PubMed] 
16. García-Alvarez, I.; Corrales, G.; Doncel-Pérez, E.; Muñoz, A.; Nieto-Sampedro, M.; Fernández-Mayoralas, A. Design and synthesis of glycoside inhibitors of glioma and melanoma growth. J. Med. Chem. 2007, 50, 364-373. [CrossRef] [PubMed]

17. Romero-Ramírez, L.; García-Álvarez, I.; Casas, J.; Barreda-Manso, M.A.; Yanguas-Casás, N.; Nieto-Sampedro, M.; Fernández-Mayoralas, A. New oleyl glycoside as anti-cancer agent that targets on neutral sphingomyelinase. Biochem. Pharmacol. 2015, 97, 158-172. [CrossRef] [PubMed]

18. Moreno-Clavijo, E.; Carmona, A.T.; Vera-Ayoso, Y.; Moreno-Vargas, A.J.; Bello, C.; Vogel, P.; Robina, I. Synthesis of novel pyrrolidine 3,4-diol derivatives as inhibitors of $\alpha$-L-fucosidases. Org. Biomol. Chem. 2009, 7, 1192. [CrossRef] [PubMed]

19. García-Alvarez, I.; Garrido, L.; Doncel-Pérez, E.; Nieto-Sampedro, M.; Fernández-Mayoralas, A. Detection of metabolite changes in C6 glioma cells cultured with antimitotic oleyl glycoside by ${ }^{1} \mathrm{H}$ MAS NMR. J. Med. Chem. 2009, 52, 1263-1267. [CrossRef] [PubMed]

20. García-Álvarez, I.; Egido-Gabás, M.; Romero-Ramírez, L.; Doncel-Pérez, E.; Nieto-Sampedro, M.; Casas, J.; Fernández-Mayoralas, A. Lipid and ganglioside alterations in tumor cells treated with antimitotic oleyl glycoside. Mol. Biosyst. 2011, 7, 129-138. [CrossRef] [PubMed]

21. Birklé, S.; Zeng, G.; Gao, L.; Yu, R.K.; Aubry, J. Role of tumor-associated gangliosides in cancer progression. Biochimie 2003, 85, 455-463. [CrossRef]

22. Lahiri, S.; Futerman, A.H. The metabolism and function of sphingolipids and glycosphingolipids. Cell. Mol. Life Sci. 2007, 64, 2270-2284. [CrossRef] [PubMed]

23. Bektas, M.; Spiegel, S. Glycosphingolipids and cell death. Glycoconj. J. 2004, 20, 39-47. [CrossRef] [PubMed]

24. García-Álvarez, I.; Groult, H.; Casas, J.; Barreda-Manso, M.A.; Yanguas-Casás, N.; Nieto-Sampedro, M.; Romero-Ramírez, L.; Fernández-Mayoralas, A. Synthesis of Antimitotic Thioglycosides: In Vitro and in vivo Evaluation of Their Anticancer Activity. J. Med. Chem. 2011, 54, 6949-6955. [CrossRef] [PubMed]

25. Chojnowska, S.; Kępka, A.; Szajda, S.D.; Waszkiewicz, N.; Bierć, M.; Zwierz, K. Exoglycosidase markers of diseases. Biochem. Soc. Trans. 2011, 39, 406-409. [CrossRef] [PubMed]

26. Driguez, H. Thiooligosaccharides in glycobiology. In Glycoscience Synthesis of Substrate Analogs and Mimetics; Driguez, H., Thiem, J., Eds.; Springer: Berlin/Heidelberg, Germany, 1997; Volume 187, pp. 85-116, ISBN 978-3-540-62032-7.

27. Kingsley, J.D.; Dou, H.; Morehead, J.; Rabinow, B.; Gendelman, H.E.; Destache, C.J. Nanotechnology: A focus on nanoparticles as a drug delivery system. J. Neuroimmune Pharmacol. 2006, 1, 340-350. [CrossRef] [PubMed]

28. Herranz, F.; Salinas, B.; Groult, H.; Pellico, J.; Lechuga-Vieco, A.; Bhavesh, R.; Ruiz-Cabello, J. Superparamagnetic Nanoparticles for Atherosclerosis Imaging. Nanomaterials 2014, 4, 408-438. [CrossRef] [PubMed]

29. Hao, R.; Xing, R.; Xu, Z.; Hou, Y.; Gao, S.; Sun, S. Synthesis, Functionalization, and Biomedical Applications of Multifunctional Magnetic Nanoparticles. Adv. Mater. 2010, 22, 2729-2742. [CrossRef] [PubMed]

30. Laurent, S.; Forge, D.; Port, M.; Roch, A.; Robic, C.; Vander Elst, L.; Muller, R.N. Magnetic Iron Oxide Nanoparticles: Synthesis, Stabilization, Vectorization, Physicochemical Characterizations, and Biological Applications. Chem. Rev. 2008, 108, 2064-2110. [CrossRef] [PubMed]

31. García-Álvarez, I.; Fernández-Mayoralas, A.; Moreno-Lillo, S.; Sánchez-Sierra, M.; Nieto-Sampedro, M.; Doncel-Pérez, E. Inhibition of glial proliferation, promotion of axonal growth and myelin production by synthetic glycolipid: A new approach for spinal cord injury treatment. Restor. Neurol. Neurosci. 2015, 33, 895-910. [CrossRef] [PubMed]

32. Wolfrom, M.L.; Conigliaro, P.J. Trifluoroacetyl as an N-protective group in the synthesis of purine nucleosides of 2-amino-2-deoxy saccharides. Carbohydr. Res. 1969, 11, 63-76. [CrossRef]

33. Herranz, F.; Morales, M.P.; Roca, A.G.; Desco, M.; Ruiz-Cabello, J. A New Method for the Rapid Synthesis of Water Stable Superparamagnetic Nanoparticles. Chem. Eur. J. 2008, 14, 9126-9130. [CrossRef] [PubMed]

34. Sun, S.; Zeng, H. Size-Controlled Synthesis of Magnetite Nanoparticles. J. Am. Chem. Soc. 2002, 124, 8204-8205. [CrossRef] [PubMed]

35. Roca, A.G.; Morales, M.P.; O'Grady, K.; Serna, C.J. Structural and magnetic properties of uniform magnetite nanoparticles prepared by high temperature decomposition of organic precursors. Nanotechnology 2006, 17, 2783-2788. [CrossRef]

36. Ahmad, S.; Riaz, U.; Kaushik, A.; Alam, J. Soft Template Synthesis of Super Paramagnetic $\mathrm{Fe}_{3} \mathrm{O}_{4}$ Nanoparticles a Novel Technique. J. Inorg. Organomet. Polym. Mater. 2009, 19, 355-360. [CrossRef] 
37. Kaushik, A.; Jayant, R.D.; Nikkhah-Moshaie, R.; Bhardwaj, V.; Roy, U.; Huang, Z.; Ruiz, A.; Yndart, A.; Atluri, V.; El-Hage, N.; et al. Magnetically guided central nervous system delivery and toxicity evaluation of magneto-electric nanocarriers. Sci. Rep. 2016, 6. [CrossRef] [PubMed]

38. Groult, H.; Ruiz-Cabello, J.; Lechuga-Vieco, A.V.; Mateo, J.; Benito, M.; Bilbao, I.; Martínez-Alcázar, M.P.; Lopez, J.A.; Vázquez, J.; Herranz, F.F. Phosphatidylcholine-Coated Iron Oxide Nanomicelles for in vivo Prolonged Circulation Time with an Antibiofouling Protein Corona. Chem. Eur. J. 2014, 20, 16662-16671. [CrossRef] [PubMed]

39. Na, H.B.; Song, I.C.; Hyeon, T. Inorganic Nanoparticles for MRI Contrast Agents. Adv. Mater. 2009, 21, 2133-2148. [CrossRef]

40. Pellico, J.; Lechuga-Vieco, A.V.; Benito, M.; García-Segura, J.M.; Fuster, V.; Ruiz-Cabello, J.; Herranz, F. Microwave-driven synthesis of bisphosphonate nanoparticles allows in vivo visualisation of atherosclerotic plaque. RSC Adv. 2015, 5, 1661-1665. [CrossRef]

41. Mejías, R.; Pérez-Yagüe, S.; Gutiérrez, L.; Cabrera, L.I.; Spada, R.; Acedo, P.; Serna, C.J.; Lázaro, F.J.; Villanueva, A.; Morales, M.D.P.; et al. Dimercaptosuccinic acid-coated magnetite nanoparticles for magnetically guided in vivo delivery of interferon gamma for cancer immunotherapy. Biomaterials 2011, 32, 2938-2952. [CrossRef] [PubMed]

42. Nasongkla, N.; Bey, E.; Ren, J.; Ai, H.; Khemtong, C.; Guthi, J.S.; Chin, S.-F.; Sherry, A.D.; Boothman, D.A.; Gao, J. Multifunctional Polymeric Micelles as Cancer-Targeted, MRI-Ultrasensitive Drug Delivery Systems. Nano Lett. 2006, 6, 2427-2430. [CrossRef] [PubMed]

43. Crespo-Castrillo, A.; Punzón, E.; de Pascual, R.; Maroto, M.; Padín, J.F.; García-Álvarez, I.; Nanclares, C.; Ruiz-Pascual, L.; Gandía, L.; Fernández-Mayoralas, A.; et al. Novel synthetic sulfoglycolipid IG20 facilitates exocytosis in chromaffin cells through the regulation of sodium channels. J. Neurochem. 2015, 135, 880-896. [CrossRef] [PubMed]

44. Schreier, S.; Malheiros, S.V.P.; de Paula, E. Surface active drugs: Self-association and interaction with membranes and surfactants. Physicochemical and biological aspects. Biochim. Biophys. Acta (BBA) Biomembr. 2000, 1508, 210-234. [CrossRef]

45. Liu, Y.; Miyoshi, H.; Nakamura, M. Nanomedicine for drug delivery and imaging: A promising avenue for cancer therapy and diagnosis using targeted functional nanoparticles. Int. J. Cancer 2007, 120, 2527-2537. [CrossRef] [PubMed]

46. Jang, S.H.; Wientjes, M.G.; Lu, D.; Au, J.L.S. Drug delivery and transport to solid tumors. Pharm. Res. 2003, 20, 1337-1350. [CrossRef] [PubMed]

47. Antonelli, A.; Sfara, C.; Battistelli, S.; Canonico, B.; Arcangeletti, M.; Manuali, E.; Salamida, S.; Papa, S.; Magnani, M. New Strategies to Prolong the in vivo Life Span of Iron-Based Contrast Agents for MRI. PLoS ONE 2013, 8, e78542. [CrossRef] [PubMed]

48. Daldrup-Link, H.E. Ten Things You Might Not Know about Iron Oxide Nanoparticles. Radiology 2017, 284, 616-629. [CrossRef] [PubMed]

49. El-Boubbou, K. Magnetic iron oxide nanoparticles as drug carriers: Clinical relevance. Nanomedicine 2018, 13, 953-971. [CrossRef] [PubMed]

50. Wáng, Y.X.J.; Idée, J.-M. A comprehensive literatures update of clinical researches of superparamagnetic resonance iron oxide nanoparticles for magnetic resonance imaging. Quant. Imaging Med. Surg. 2017, 7, 88-122. [CrossRef] [PubMed]

51. Cortajarena, A.L.; Ortega, D.; Ocampo, S.M.; Gonzalez-García, A.; Couleaud, P.; Miranda, R.; Belda-Iniesta, C.; Ayuso-Sacido, A. Engineering Iron Oxide Nanoparticles for Clinical Settings. Nanobiomedicine 2014, 1, 2. [CrossRef] [PubMed]

52. Yang, J.; Lee, T.-I.; Lee, J.; Lim, E.-K.; Hyung, W.; Lee, C.-H.; Song, Y.J.; Suh, J.-S.; Yoon, H.-G.; Huh, Y.-M.; et al. Synthesis of Ultrasensitive Magnetic Resonance Contrast Agents for Cancer Imaging Using PEG-Fatty Acid. Chem. Mater. 2007, 19, 3870-3876. [CrossRef]

(c) 2018 by the authors. Licensee MDPI, Basel, Switzerland. This article is an open access article distributed under the terms and conditions of the Creative Commons Attribution (CC BY) license (http:// creativecommons.org/licenses/by/4.0/). 